\title{
A High-Sensitivity and Broad-Range SPR Glucose Sensor Based on Improved Glucose Sensitive Membranes
}

\author{
Yinquan YUAN*, Na YUAN, Dejing GONG, and Minghong YANG** \\ National Engineering Laboratory for Fiber Optic Sensing Technology, Wuhan University of Technology, Wuhan 430070, \\ China \\ *Corresponding authors: Yinquan YUAN and \\ E-mail: ymyyq@whut.edu.cn and \\ Minghong YANG \\ minghong.yang@whut.edu.cn
}

\begin{abstract}
An improved glucose sensitive membrane (GSM) is prepared by immobilizing glucose oxidase (GOD) onto a mixture of silica mesocellular foams (SiMCFs) and $\mathrm{SiO}_{2}$ nanoparticles (SiNPs) and then trapping it in a polyvinyl alcohol (PVA) gel. The membrane is coated onto a gold-glass sheet to create a surface plasmon resonance (SPR) sensor. A series of experiments are conducted to determine the optimized parameters of the proposed GSM. For a GSM with a component ratio of SiMCFs: $\operatorname{SiNPs}=7: 3$ (mass rate), the resonance angle of the sensor decreases from $68.57^{\circ}$ to $63.36^{\circ}$, and the average sensitivity is $0.026 \%(\mathrm{mg} / \mathrm{dL})$ in a glucose concentration range of $0 \mathrm{mg} / \mathrm{dL}-$ $200 \mathrm{mg} / \mathrm{dL}$. For a GSM with a component ratio of SiMCFs : SiNPs $=5: 5$ (mass rate), the resonance angle of the sensor decreases from $67.93^{\circ}$ to $63.50^{\circ}$, and the sensitivity is $0.028^{\circ} /(\mathrm{mg} / \mathrm{dL})$ in a glucose concentration range of $0 \mathrm{mg} / \mathrm{dL}-160 \mathrm{mg} / \mathrm{dL}$. These data suggest that the sensor proposed in this study is more sensitive and has a broader measurement range compared with those reported in the literature to date.
\end{abstract}

Keywords: Surface plasmon resonance sensor; glucose sensitive membrane; immobilized enzyme; silica mesocellular foams

Citation: Yinquan YUAN, Na YUAN, Dejing GONG, and Minghong YANG, "A High-Sensitivity and Broad-Range SPR Glucose Sensor Based on Improved Glucose Sensitive Membranes," Photonic Sensors, 2019, 9(4): 309-316.

\section{Introduction}

In recent years, optical glucose sensors based on the change in the refractive index (RI) of a sensitive membrane have attracted attention due to the increasing need for glucose detection and diagnosis of diabetes. The optical glucose sensors based on a change in the refractive index primarily use optical fiber grating sensors [1, 2] and surface plasmon resonance (SPR) sensors [3-9]. SPR is a kind of optical excitation at the site of interference of the surface plasmon wave between a layer of noble metal and a dielectric layer. The most commonly used SPR sensors are prism-based SPR sensors [3-6] and optical fiber SPR sensors [7-9]. To achieve highly selective optical glucose sensors, the use and immobilization of glucose oxidase (GOD) on a support produce stability, reusability, and high activity $[10,11]$. Common methods used to immobilize GOD are adsorption [12], encapsulation $[13,14]$, and chemical crosslinking $[15,16]$.

The optical properties and adsorption kinetics of matrix film containing immobilized GOD directly affect the performance of optical glucose sensors 
and therefore can be used as a glucose sensitive membrane (GSM). Previous studies report GOD which is immobilized on $\mathrm{SiO}_{2}$ nanoparticles (SiNPs) and trapped in polyacrylamide (PAM) gel to form GSMs [5]. The sensitivity of the prism-based glucose sensor is $0.019^{\circ} /(\mathrm{mg} / \mathrm{dL})$, and the optical fiber glucose sensor is approximately $0.14 \mathrm{~nm} /(\mathrm{mg} / \mathrm{dL})$ in a linear range of $0 \mathrm{mg} / \mathrm{dL}$ $80 \mathrm{mg} / \mathrm{dL}$. Recently, covalent immobilization of GOD on silica mesocellular foams (SiMCFs), where the SiMCFs are composed of spherical mesocells of uniform size, is disorderly interconnected through uniform windows to form a continuous 3-dimentional (3D) pore system. Having both cells and windows larger than the dimensions of GOD, the SiMCFs increase immobilization and achieve a good activity of GOD [17, 18]. GOD has also been immobilized onto SiMCFs and trapped in PAM gel. In this system, a sensitivity of $0.0135^{\circ} /(\mathrm{mg} / \mathrm{dL})$ in the linear range of $0 \mathrm{mg} / \mathrm{dL}-160 \mathrm{mg} / \mathrm{dL}$ is achieved [6]. So the structure of the nanoparticles used to immobilize GOD is vital for the optimal sensitivity and measuring range of the sensors.

The polymer materials used to trap the immobilized GOD onto nanoparticles are vital too, due to the adsorption characteristics of the GSM primarily dependent on the adsorption ability of the polymer membrane. PAM gel film is stable and biocompatible. Moreover, its thickness and pore size can be manipulated to produce an optimal matrix [19]. A borate polymer in SPR sensors has been reported, which has no immunogenicity or cytotoxicity, and stable physical and chemical properties [20]. There are many polymer materials that satisfy the need of stability and biocompatibility which could be used as embedding materials for GOD. To improve the performance of optical glucose sensors, investigations into improved immobilization nanoparticles and better polymer embedding materials are needed. In this study, an improved GSM in which GOD is covalently immobilized in a mixture of SiMCFs and SiNPs, and then entrapped in the polyvinyl alcohol (PVA) gel, is proposed. Based on a series of SPR sensing experiments, the optimum parameters, sensitivity, and measurement range of the sensors are determined.

\section{Experiment}

\subsection{Immobilization of GOD onto SiMCFs and SiNPs}

The immobilization of GOD onto SiMCFs and SiNPs is important in achieving the optimal performance of the sensors. Reagents and materials, the immobilization methods of GOD on the mixture of SiMCFs and SiNPs, are the same with those in $[5,6]$. To obtain an optimized component ratio, the total activities of the immobilized GOD onto SiMCFs and SiNPs corresponding to different component rates were measured using an ultraviolet-visible (UV-VIS) spectrometer as follows. Step 1: $3.5 \mathrm{mg}$ of 4-aminoantipyrine (4-APP) and $3.5 \mathrm{mg}$ of horseradish peroxidase (HRP) were added to $20 \mathrm{~mL}$ of phosphate buffer solution (PBS) $(0.1 \mathrm{~mol}, \mathrm{pH}=7)$, and $1 \mathrm{~mL}$ of $3 \%$ phenol solution was added dropwise and stirred well to form Solution A, which was stored at $4{ }^{\circ} \mathrm{C}$. Step 2: $100 \mathrm{mg}$ of D-glucose was added to $100 \mathrm{~mL}$ of PBS $(0.1 \mathrm{~mol}$, $\mathrm{pH}=7$ ) producing a $100 \mathrm{mg} / \mathrm{dL}$ glucose solution, Solution B, which was stored at $4{ }^{\circ} \mathrm{C}$. Step 3: $40 \mathrm{mg}$ of the immobilized GOD onto SiMCFs and SiNPs was dispersed into $4 \mathrm{~mL}$ of PBS $(\mathrm{pH}=7)$, Solution C. Step 4: $1.5 \mathrm{~mL}$ of Solution A and $1.5 \mathrm{~mL}$ of Solution $\mathrm{B}$ were mixed in a cuvette, and then $80 \mu \mathrm{L}$ of Solution $\mathrm{C}$ was added. The glucose and water were catalyzed by $\mathrm{GOD}$ to produce $\mathrm{H}_{2} \mathrm{O}_{2}$, and $\mathrm{H}_{2} \mathrm{O}_{2}$, 4-AAP, and phenol was catalyzed by HRP to generate red quinone imide. Step 5: The changes in the absorbance of red quinone imide at $510 \mathrm{~nm}$ corresponding to different component rates were measured, and then the activities of the immobilized GOD in the mixture of SiMCFs and SiNPs 
corresponding to different component rates were calculated and depicted in Fig. 1, which showed that the optimum component ratio of SiMCFs : SiNPs was $7: 3$ (mass rate).

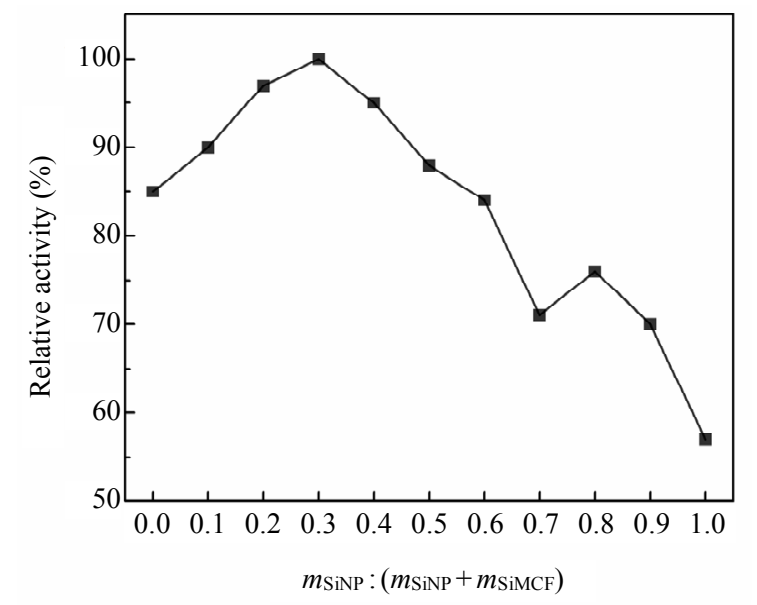

Fig. 1 Activity of GOD@(SiMCFs+SiNPs).

\subsection{Choose of trapping polymer}

Three polymer membranes were prepared as follows: (1) Pure PVA membrane: $4 \mathrm{~g}$ of PVA was dissolved in $50 \mathrm{~mL}$ of deionized water and stirred vigorously at $90^{\circ} \mathrm{C}$ for $4 \mathrm{~h}$, producing an $8 \%$ PVA solution. Then, $100 \mu \mathrm{L}$ PVA solution was transferred to the surface of a gold sheet, and a PVA film was achieved using spin coating. (2) Pure PAM membrane: $0.29 \mathrm{~g}$ acrylamide and $0.01 \mathrm{~g}$ diacrylamide were added to $1 \mathrm{~mL}$ of PBS and stirred for $30 \mathrm{~min} ; 10 \%$ ammonium persulfate solution was added and stirred for $5 \mathrm{~min}$; $\mathrm{N}$-tetramethylethylenediamine (TEMED) was added to initiate polymerization, $100 \mu \mathrm{L}$ of PAM solution was transferred to the surface of a gold sheet, and a PAM film was produced using spin coating. (3) Pure cellulose acetate (CA) membrane: $0.09 \mathrm{~g}$ CA was dissolved in $3 \mathrm{~mL}$ of acetone slowly and stirred at room temperature for $12 \mathrm{~h}, 100 \mu \mathrm{L}$ CA solution was transferred to the surface of a gold sheet, and the CA film was produced using spin coating.

To measure the adsorption performance for glucose of the three polymer films, UV-VIS absorption measurement was performed as follows. Firstly, $3.5 \mathrm{mg}$ of 4-APP and $3.5 \mathrm{mg}$ of horseradish peroxidase (HRP) were added to $20 \mathrm{~mL}$ PBS (0.1 mol, $\mathrm{pH}=7)$. After mixing, $1 \mathrm{~mL}$ of $3 \%$ phenol solution was added to the mixture and stored at $4{ }^{\circ} \mathrm{C}$, which is Solution A. Secondly, $100 \mathrm{mg}$ of D-glucose was added to $100 \mathrm{~mL}$ PBS $(0.1 \mathrm{~mol}, \mathrm{pH}=7)$ to produce $100 \mathrm{mg} / \mathrm{dL}$ glucose solution and stirred, which is Solution B. Thirdly, $15 \mathrm{~mL}$ of Solution B was injected into three clean Petri dishes, and PVA, PAM, and CA membranes were placed in the Petri dishes to soak for $30 \mathrm{~min}$. Fourthly, $5 \mathrm{~mL}$ of Solution A was added to three weighing bottles, the PVA, PAM, and CA membranes containing adsorbed glucose were transferred into the weighing bottles, and $100 \mu \mathrm{L}$ of GOD $(1 \mathrm{mg} / \mathrm{mL})$ was added to each weighing, which is Solution C. $3 \mathrm{~mL}$ of Solution C from each bottle was placed into three cuvettes and the UV-VIS absorption spectra (UV-2450 Spectrophotometer, Shimadzu, Japan) determined. The UV-VIS absorption spectra of PVA, PAM, and CA membranes saturated with glucose are given in Fig. 2, which shows that the PVA film has the greatest adsorption ability for glucose.

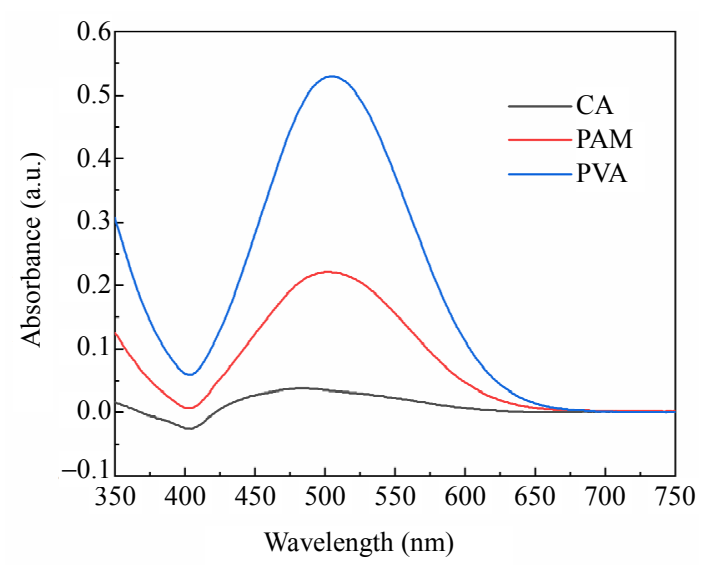

Fig. 2 Absorption spectra of pure PVA, PAM, and CA membranes.

\subsection{Apparatus and probe}

Figure 3 shows the schematic diagram of the prism based SPR sensor. Based on the Kretschmann structure and angular interrogation, the SPR sensor consisted of a monochromatic light source $(650 \mathrm{~nm}$, emitted by laser diode), a semi-circular prism, a glucose sensing probe, a reaction cell, two 
photoelectric detectors, and a microcomputer $[5,6]$. The glucose sensing probe consisted of a gold-glass sheet and a GSM: the latter was made of the GOD crosslinked onto the mixture of SiMCFs and SiNPs and the trapping polymer (PVA) using a sol-gel method. The thickness of square glass sheet $(18 \mathrm{~mm}$ $\times 18 \mathrm{~mm}$ ) was approximately $0.20 \mathrm{~mm}$. The preparation steps of a GSM were as following. Step 1: To generate a hydrophilic surface, the gold-glass sheet was rinsed with ethanol and acetone several times and soaked in PBS for $30 \mathrm{~min}$. Step 2: $4 \mathrm{~g}$ of PVA was dissolved in $50 \mathrm{~mL}$ of deionized water, heated in a water bath at $90{ }^{\circ} \mathrm{C}$ and stirred for $4 \mathrm{~h}$, and $8 \%$ of PVA solution was obtained. Step 3: The immobilized GOD in the mixture of SiMCFs and SiNPs was added to $1 \mathrm{~mL}$ of PVA solution and stirred slowly for $1 \mathrm{~h}$. Step 4: The probes were produced by coating GSM on the surface of a gold-glass sheet using spin coating, dried at $25^{\circ} \mathrm{C}$ for a few minutes and stored at $4^{\circ} \mathrm{C}$, to prevent the loss of GOD activity.

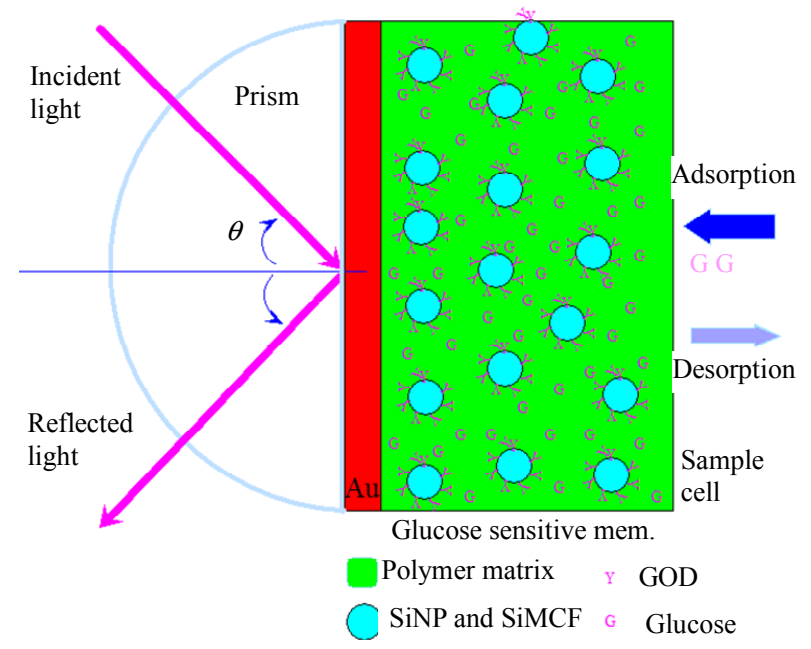

Fig. 3 Schematic diagram of the prism based SPR sensor.

A Fourier transform infrared (FT-IR) spectrometer (Thermoelectron Scientific Instruments, Nicolet6700, US) was used to identify whether the GOD was immobilized on the SiNPs and SiMCFs, and entrapped in the PVA film. As shown in Fig. 4, a spectrum of the GOD shows four infrared bands with central positions at $3300 \mathrm{~cm}^{-1}$ (amide A), $1657 \mathrm{~cm}^{-1}$ (amide I), $1538 \mathrm{~cm}^{-1}$ (amide II) and
$1246 \mathrm{~cm}^{-1}$ (amide III). The peak at $3300 \mathrm{~cm}^{-1}$ can be assigned to amide $\mathrm{A}$, with a shoulder at $3064 \mathrm{~cm}^{-1}$. A peak at $1657 \mathrm{~cm}^{-1}$ corresponds to $\mathrm{C}=\mathrm{O}$ stretching vibrations of the peptide linkages in the backbone, and the band at $1538 \mathrm{~cm}^{-1}$ is attributed to the combination of $\mathrm{C}-\mathrm{N}$ stretching and $\mathrm{N}-\mathrm{H}$ in-plane bending.

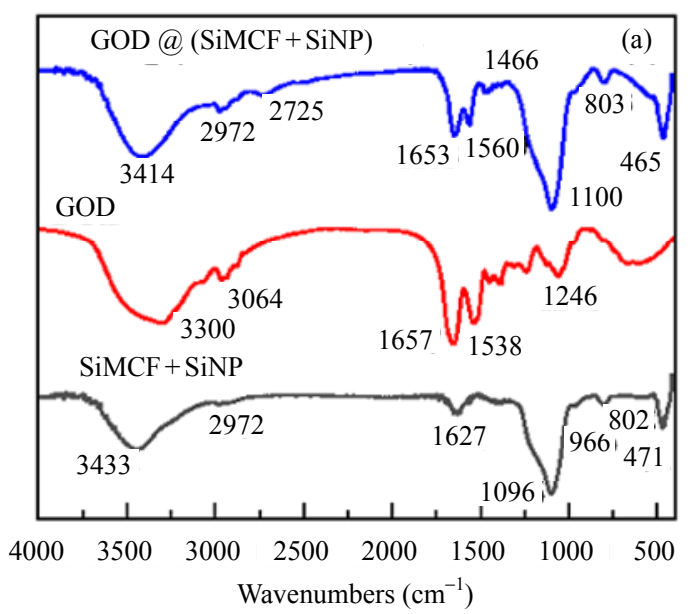

(a)

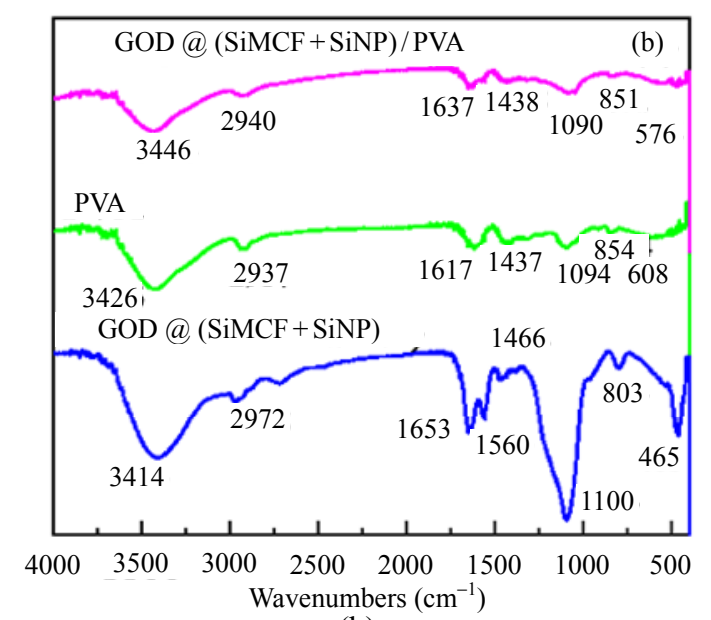

(b)

Fig. 4 FT-IR spectra of the GOD@(SiMCFs + SiNPs)/PVA membranes.

In the spectrum of the mixture of SiMCFs and SiNPs, the strong and broad peak at $3433 \mathrm{~cm}^{-1}$ is the OH stretching vibration peak, the peak at $1096 \mathrm{~cm}^{-1}$ is the stretching vibration peak of asymmetric $\mathrm{Si}-\mathrm{O}-\mathrm{Si}$, the peak at $966 \mathrm{~cm}^{-1}$ is the symmetric stretching vibration peak of $\mathrm{Si}-\mathrm{OH}$, the peak at $802 \mathrm{~cm}^{-1}$ is the symmetric stretching peak of Si-O-Si, and the peak at $471 \mathrm{~cm}^{-1}$ is the bending vibration 
peak of symmetric Si-O-Si. The presence of these peaks indicates the existence of SiMCFs + SiNPs mixed particles. From the PVA spectrum, the strong and broad absorption peak at $3426 \mathrm{~cm}^{-1}$ is the stretching vibration of $-\mathrm{OH}$ in the form of the association between PVA molecules, and $2937 \mathrm{~cm}^{-1}$ is the characteristic absorption peak of the asymmetric stretching vibration of $\mathrm{C}-\mathrm{H}$. The peak at $1617 \mathrm{~cm}^{-1}$ is the shear vibration of $\mathrm{OH}, 1437 \mathrm{~cm}^{-1}$ is the bending vibration peak of $\mathrm{CH}_{2}$, the stretching vibration peak of the secondary alcohol hydroxyl group $\mathrm{C}-\mathrm{O}$ is at $1094 \mathrm{~cm}^{-1}$, and the stretching vibration absorption peak of terminal vinyl $\mathrm{C}=\mathrm{C}$ is at $854 \mathrm{~cm}^{-1}$. In the infrared spectrum of GOD @ (SiMCFs + SiNPs) / PVA, all characteristic peaks of PVA and GOD@ (SiMCFs + SiNPs) are observed, indicating the immobilized GOD is embedded in the PVA film.

\section{Results and discussion}

\subsection{Effect of GOD content}

The effect of GOD content is investigated in solutions where the $\mathrm{pH}$ is fixed between 6.5 and 7.0. Figure 5 shows the variation in resonance angles with the concentration of glucose at different GOD contents $(3 \mathrm{mg} / \mathrm{mL}, 4 \mathrm{mg} / \mathrm{mL}, 5 \mathrm{mg} / \mathrm{mL}, 6 \mathrm{mg} / \mathrm{mL}$, and $7 \mathrm{mg} / \mathrm{mL}$ ). The sensitivity increases with an increase in the GOD content and with a maximum of $0.026 \%(\mathrm{mg} / \mathrm{dL})$ at the GOD content of approximately $5.0 \mathrm{mg} / \mathrm{mL}$. An increase in the sensitivity could be due to more GOD results in greater quantities of glucose catalysis to produce gluconic acid and $\mathrm{H}_{2} \mathrm{O}_{2}$, resulting in the greater changes in the RI of sensing film. As the GOD content exceeds the saturation value $(5.0 \mathrm{mg} / \mathrm{mL})$, a further increase in the GOD content could cause the special steric hindrance which reduces the enzymatic activity.

\subsection{SPR spectra and sensitivity}

Three composite GSMs are prepared by immobilizing the GOD onto a mixture of SiMCFs and SiNPs with different component ratios $(7: 3,5: 5$, and $3: 7$ ), and then trapping in PVA gels under the optimum conditions $(5.0 \mathrm{mg} / \mathrm{mL}$ of GOD content, $2.5 \%$ vol of APTES, $0.15 \mathrm{M}$ of EDC and $0.0375 \mathrm{M}$ of NHS). When the SPR probes coated with three composite GSMs are in contact with PBSs containing various concentrations of glucose $(\mathrm{pH}=$ 7.0), their SPR spectra corresponded to the different concentrations of glucose $(0 \mathrm{mg} / \mathrm{dL}, 40 \mathrm{mg} / \mathrm{dL}$, $80 \mathrm{mg} / \mathrm{dL}, 120 \mathrm{mg} / \mathrm{dL}, 160 \mathrm{mg} / \mathrm{dL}, 200 \mathrm{mg} / \mathrm{dL}$, and $240 \mathrm{mg} / \mathrm{dL}$ ) are shown in Figs. 6(a) - 6(c), and corresponding shifts of resonance angle are shown in Fig. 7.

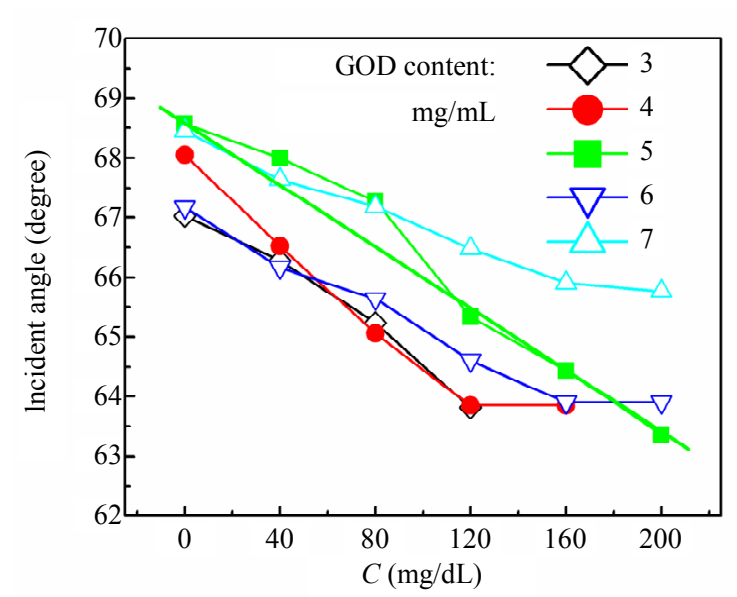

Fig. 5 Effect of the GOD content on the sensitivity, where the content of GOD increases from $3 \mathrm{mg} / \mathrm{mL}$ to $7 \mathrm{mg} / \mathrm{mL}$.

At a component ratio of $m_{\mathrm{SiMCF}}: m_{\mathrm{SiNP}}=7: 3$ (square-line), the resonance angle of the sensor decreases from $68.57^{\circ}$ to $63.36^{\circ}$ as the glucose concentration increases from $0 \mathrm{mg} / \mathrm{dL}$ to $200 \mathrm{mg} / \mathrm{dL}$, and the average sensitivity is $0.026^{\circ} /(\mathrm{mg} / \mathrm{dL})$ in a glucose concentration range of $0 \mathrm{mg} / \mathrm{dL}-200 \mathrm{mg} / \mathrm{dL}$. At the ratio of $m_{\mathrm{SiMCF}}: m_{\mathrm{SiNP}}=5: 5$ (circle-line), the resonance angle of the sensor decreases from $67.93^{\circ}$ to $63.50^{\circ}$ approximately linearly as the glucose concentration increases from $0 \mathrm{mg} / \mathrm{dL}$ to $160 \mathrm{mg} / \mathrm{dL}$, and the sensitivity is $0.028 \%(\mathrm{mg} / \mathrm{dL})$ in a glucose concentration range of $0 \mathrm{mg} / \mathrm{dL}-160 \mathrm{mg} / \mathrm{dL}$, where the solid line is drawn according to the fitting equation of $\theta_{\text {res }}(C)-\theta_{\text {res }}(0)=0.128-0.02795 C$ $\left(R^{2}=0.9937\right)$. 


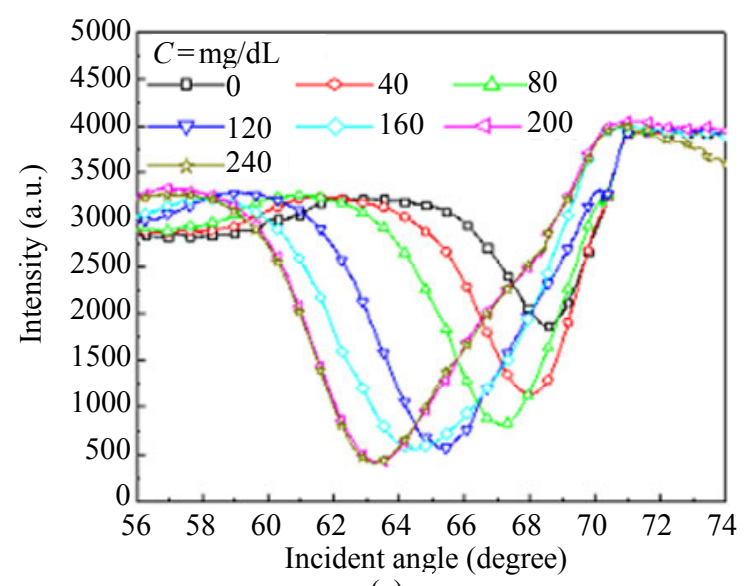

(a)

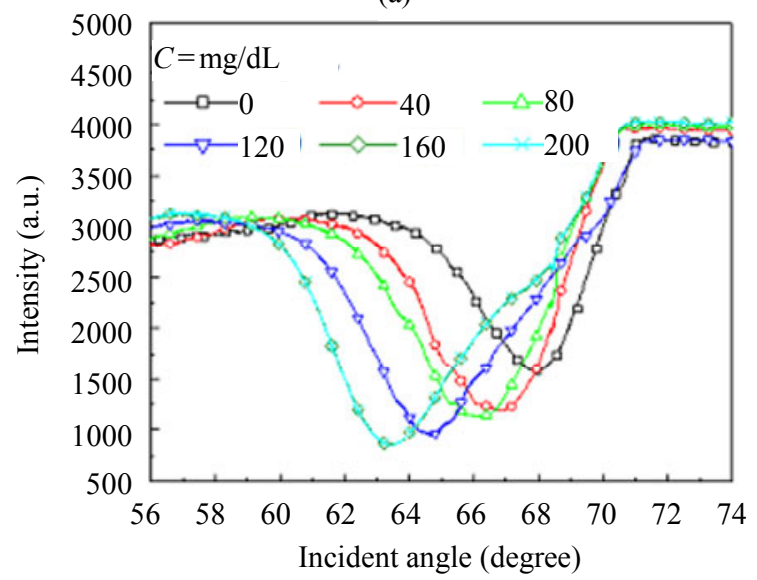

(b)

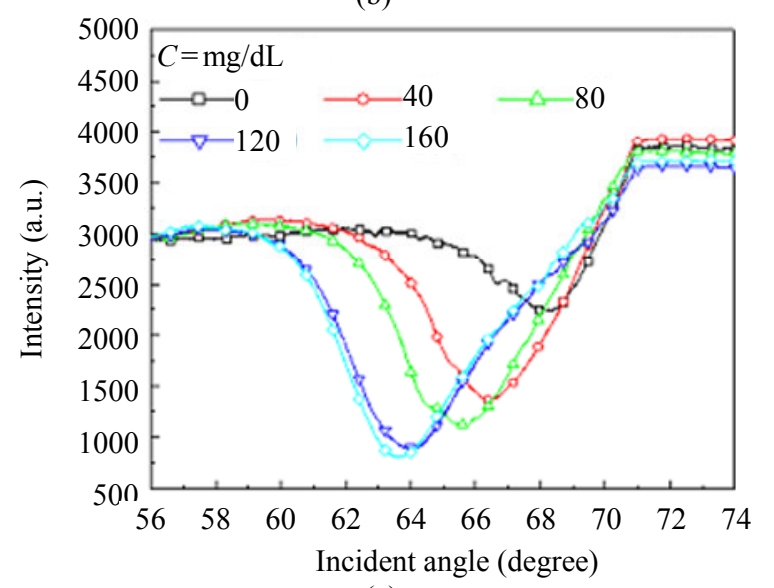

(c)

Fig. 6 Resonance spectra of the GSMs with different component rates of SiMCFs and SiNPs: (a) $7: 3$, (b) $5: 5$, and (c) $3: 7$.

These data suggest better results compared with that reported in the literature. For example, previously reported work in which GOD was immobilized on SiNPs and trapped in PAM gel had an SPR sensitivity of $0.019^{\circ} /(\mathrm{mg} / \mathrm{dL})$ in the linear range $0 \mathrm{mg} / \mathrm{dL}-80 \mathrm{mg} / \mathrm{dL}$ [5]; when GOD was immobilized onto SiMCFs and trapped in PAM gel, and the sensitivity was $0.0135^{\circ} /(\mathrm{mg} / \mathrm{dL})$, in the linear range of $0 \mathrm{mg} / \mathrm{dL}-160 \mathrm{mg} / \mathrm{dL}$ [6].

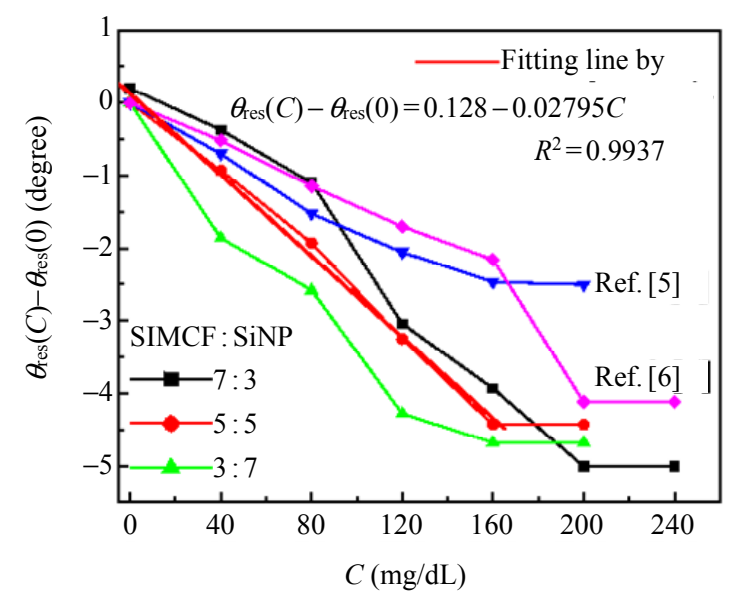

Fig. 7 Resonance angles of the GSMs with different component rates of SiMCFs and SiNPs: (a) 7:3, (b) 5:5, and (c) $3: 7$.

An increases in the measurement range and sensitivity maybe is due to a change in the adsorption performance of the GSM. In the proposed GSM, SiMCFs are porous materials, and SiNPs are solid spherical particles. When the component ratio in the mixture of SiMCFs and SiNPs changes, the maximum adsorption capacity and adsorption constant of glucose molecules in GSM change complicatedly. On the one hand, SiMCFs have much more Brunauer-Emmett-Teller (BET) surface area than SiNPs, so the immobilization of GOD onto SiMCFs could increase the maximum adsorption capacity of glucose molecules in GSM. On the other hand, the amination of 3-Aminopropyltriethoxysilane (APTES) in the inner surface of SiMCFs is more difficult than that on the surface of SiNPs, meanwhile, there is a greater resistance in the pores of SiMCFs when GOD and glucose molecules enter into the porous materials, which maybe affect the adsorption constants of GSM for glucose molecules. The above two factors maybe decide that the maximum adsorption capacity and adsorption constant of GSM for glucose molecules reach their maximum as the 
component ratio of SiMCFs and SiNPs reaches a certain proportion. The experiments show that the GSM with the mass ratio of $m_{\mathrm{SiMCF}}: m_{\mathrm{SiNP}}=7: 3$ has the average sensitivity of $0.026 \%(\mathrm{mg} / \mathrm{dL})$ and measurement range of $0 \mathrm{mg} / \mathrm{dL}-200 \mathrm{mg} / \mathrm{dL}$, while the GSM with the mass ratio of $m_{\mathrm{SiMCF}}: m_{\mathrm{SiNP}}=$ $5: 5$ has the average sensitivity of $0.028^{\circ} /(\mathrm{mg} / \mathrm{dL})$ and measurement range of $0 \mathrm{mg} / \mathrm{dL} \quad-$ $160 \mathrm{mg} / \mathrm{dL}$.

\subsection{Adsorption models of GSMs}

The adsorption isotherm of the GSM with the component ratio of $m_{\mathrm{SiMCF}}: m_{\mathrm{SiNP}}=5: 5$ is investigated since this membrane produces a good linear relationship between the shift of resonance angle and glucose concentration. Firstly, the SPR sensor working in the angle interrogation mode is simulated, and the resonance angle is found to have a linear relationship with the film RI in the range of $1.410-1.480$.

$$
\theta_{\text {res }}\left(n_{f}\right)-\theta_{\text {res }}\left(n_{f 0}\right)=\gamma\left(n_{f}-n_{f 0}\right)
$$

where $\gamma=88.78 \mathrm{RIU}^{-1}$ and $R^{2}=0.9987$. Then, the shift in the resonance angle can be rewritten as follows [5]:

$$
\left|\Delta \theta_{\text {res }}\right|=\gamma\left(n_{f 0}-n_{\mathrm{ga}}\right)\left(1+v_{\mathrm{H}_{2} \mathrm{O}_{2}} / v_{\mathrm{ga}}\right) \phi_{g}(C)
$$

by which, the volume fraction of glucose into the GSM can be expressed as follows:

$$
\phi_{g}(C)=\frac{\left|\Delta \theta_{\mathrm{res}}(C)\right|}{\gamma\left(n_{f 0}-n_{\mathrm{ga}}\right)\left(1+v_{\mathrm{H}_{2} \mathrm{O}_{2}} / v_{\mathrm{ga}}\right)} .
$$

For the GSMs, $n_{f 0}=1.480, n_{\mathrm{ga}}=1.416, v_{\mathrm{ga}}=$ $111.2 \mathrm{~cm}^{3} / \mathrm{mol}, \quad v_{\mathrm{H}_{2} \mathrm{O}_{2}}=23.5 \mathrm{~cm}^{3} / \mathrm{mol}$, and $\phi_{\mathrm{g}}(C)=$ $0.1463\left|\Delta \theta_{\text {res }}(C)\right|$ are considered. Based on the changes in resonance angles corresponding to the different concentrations of glucose, the relationship between the volume fraction of glucose on the GSM and the glucose concentration is shown by squares in Fig. 8.

For comparison, the volume fractions of glucose into the GSMs based on GOD@SiNP/PAM [5] and GOD@SiMCF/PAM [6] are shown by circles and up-triangles also. It can be seen that the volume fraction of glucose into the GSM has a linear relationship with the concentration of glucose, being lower than approximately $160 \mathrm{mg} / \mathrm{dL}$. The solid line is drawn using a Freundlich isotherm models. The adsorption constant of the GSM based on GOD @ $(\operatorname{SiMCF}+\operatorname{SiNP}) / \mathrm{PVA}\left(K_{F}=4.1 \times 10^{-3}\right)$ is higher than those of the GSMs based on GOD @ SiNP/PAM and GOD@SiMCF / PAM $\left(K_{F}=3.0 \times 10^{-3}\right.$, $\left.2.0 \times 10^{-3}\right)$.

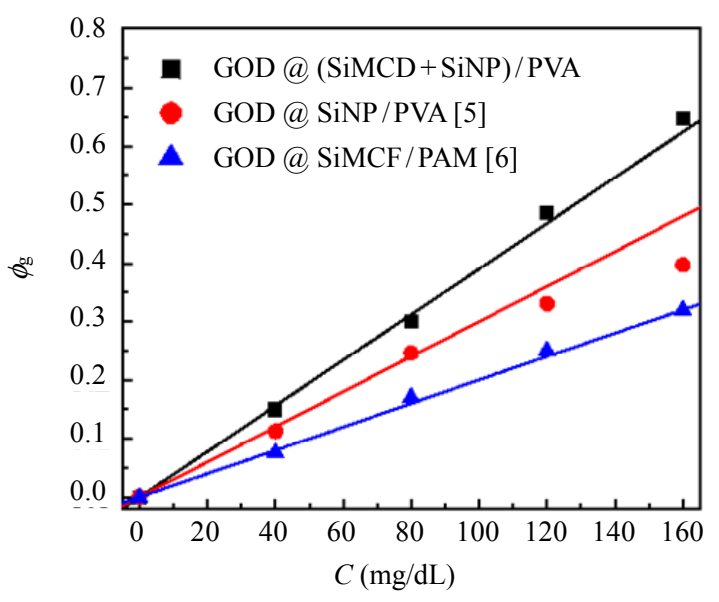

Fig. 8 Volume fraction of the glucose in the GSM versus concentration of the glucose.

\section{Conclusions}

In this study, an improved GSM is prepared using immobilized GOD onto a mixture of SiNPs and SiMCFs and then trapping them in PVA gel for use in an optical glucose sensor. For a GSM with a component ratio of SiMCFs: SiNPs $=3: 7$ (mass rate), the resonance angle of the sensor decreases from $68.57^{\circ}$ to $63.36^{\circ}$, and the average sensitivity is $0.026^{\circ} /(\mathrm{mg} / \mathrm{dL})$ in a glucose concentration range of $0 \mathrm{mg} / \mathrm{dL}-200 \mathrm{mg} / \mathrm{dL}$. For a GSM with the component ratio of SiMCFs: $\mathrm{SiNPs}=5: 5$ (mass rate), the resonance angle of the sensor decreases from $67.93^{\circ}$ to $63.50^{\circ}$, and the sensitivity is $0.028 \%(\mathrm{mg} / \mathrm{dL})$ in a glucose concentration range of $0 \mathrm{mg} / \mathrm{dL}-160 \mathrm{mg} / \mathrm{dL}$. Therefore, the data suggest that the sensor proposed in this study is more sensitive and has a broader range of selectively compared with those reported in the literatures to date. 


\section{Acknowledgement}

This work was funded by the National Natural Science Foundation of China (Grant No. 61575151).

Open Access This article is distributed under the terms of the Creative Commons Attribution 4.0 International License (http://creativecommons.org/licenses/by/4.0/), which permits unrestricted use, distribution, and reproduction in any medium, provided you give appropriate credit to the original author(s) and the source, provide a link to the Creative Commons license, and indicate if changes were made.

\section{References}

[1] B. B. Luo, Z. J. Yan, Z. Y. Sun, Y. Liu, M. F. Zhao, and L. Zhang, "Biosensor based on excessively tilted fiber grating in thin-cladding optical fiber for sensitive and selective detection of low glucose concentration," Optics Express, 2015, 23(25): 32429-32440.

[2] A. Deep, U. Tiwari, P. Kumar, V. Mishra, S. C. Jain, N. Singh, et al., "Immobilization of enzyme on long period grating fibers for sensitive glucose detection," Biosensors and Bioelectronics, 2012, 33(1): 190-195.

[3] W. W. Lam, L. H. Chu, C. L. Wong, and Y. T. Zhang, "A surface plasmon resonance system for the measurement of glucose in aqueous solution," Sensors and Actuators B: Chemical, 2005, 105(2): 138-143.

[4] D. Li, D. Yang, J. Yang, Y. Lin, Y. J. Sun, H. X. Yu, et al., "Glucose affinity measurement by surface plasmon resonance with borate polymer binding," Sensors and Actuators A: Physical, 2015, 222: 58-66.

[5] X. Yang, Y. Q. Yuan, Z. C. Dai, F. Liu, and J. Huang, "Optical property and adsorption isotherm models of glucose sensitive membrane based on prism SPR sensor," Sensors and Actuators B: Chemical, 2016, 237: $150-168$.

[6] Y. Y. Li, Y. Q. Yuan, D. J. Gong, W. B. Hu, and M. H. Yang, "A SPR glucose sensor based on immobilized glucose oxidases and silica mesocellular foams," IEEE Sensors Journal, 2018, 18: 2229-2235.

[7] S. Singh and B. D. Gupta, "Fabrication and characterization of a surface plasmon resonance based fiber optic sensor using gel entrapment technique for the detection of low glucose concentration," Sensors and Actuators B: Chemical, 2013, 177: 589-595.

[8] D. C. Li, J. W. Wu, P. Wu, Y. Lin, Y. J. Sun, R. Zhu, et al., "Affinity based glucose measurement using fiber optic surface plasmon resonance sensor with surface modification by borate polymer," Sensors and Actuators B: Chemical, 2015, 213: 295-304.
[9] Y. Q. Yuan, X. Yang, D. J. Gong, F. Liu, W. B. Hu, W. Q. Cai, et al., "Investigation for terminal reflection optical fiber SPR glucose sensor and glucose sensitive membrane with immobilized GODs," Optics Express, 2017, 25(4): 3884-3898.

[10] A. Y. Khan, S. B. Noronha, and R. Bandyopadhyaya, "Glucose oxidase enzyme immobilized porous silica for improved performance of a glucose biosensor," Biochemical Engineering Journal, 2014, 91: 78-85.

[11] H. Ikemoto, Q. J. Chi, and J. Ulstrup, "Stability and catalytic kinetics of horseradish peroxidase confined in nanoporous SBA-15," The Journal of Physical Chemistry C, 2010, 114: 1840-1846.

[12] M. Ferreira, P. A. Fiorito, O. N. Oliveira Jr., and S. I. C. de Torresi, "Enzyme-mediated amperometric biosensors prepared with the Layer-by-Layer (LbL) adsorption technique," Biosensors and Bioelectronics, 2004, 19(12): 1611-1615.

[13] J. Livage, T. Coradin, and C. Roux, "Encapsulation of biomolecules in silica gels," Journal of Physics Condensed Matter, 2001, 13(33): R673-R691.

[14] S. P. Usha, A. M. Shrivastav, and B. D. Gupta, "FO-SPR based dextrose sensor using $\mathrm{Ag} / \mathrm{ZnO}$ nanorods $/ \mathrm{GO}_{\mathrm{x}}$ for insulinoma detection," Biosensors and Bioelectronics, 2016, 85: 986-995.

[15] J. Huang, H. Wang, D. P. Li, W. Q. Zhao, L. Y. Ding, and Y. Han. "A new immobilized glucose oxidase using $\mathrm{SiO}_{2}$ nanoparticles as carrier," Materials Science and Engineering: C, 2011, 31(7): 1374-1378.

[16] N. Balistreri, D. Gaboriaua, C. Jolivalt, and F. Launay, "Covalent immobilization of glucose oxidase on mesocellular silica foams: characterization and stability towards temperature and organic solvents," Journal of Molecular Catalysis B: Enzymatic, 2016, 127: 26-33.

[17] M. Hartmann and D. Jung, "Biocatalysis with enzymes immobilized on mesoporous hosts: the status quo and future trends," Journal of Materials Chemistry, 2010, 20(5): 844-857.

[18] V. Zlateski, T. C. Keller, J. P. Ramirez, and R. N. Grass, "Immobilizing and de-immobilizing enzymes on mesoporous silica," RSC Advances, 2015, 5(106): 87706-87712.

[19] S. Singh, S. K. Mishra, and B. D. Gupta, "SPR based fibre biosensor for phenolic compounds using immobilization of tyrosinase in polyacrylamide gel," Sensors and Actuators B: Chemical, 2013, 186: 388-395.

[20] S. Q. Li, E. N. Davis, J. Anderson, Q, Lin, and Q. Wang, "Development of boronic acid grafted random copolymer sensing fluid for continuous glucose monitoring," Biomacromolecules, 2008, 10(1): 113-118. 